\title{
Compositional characteristics and antibacterial activity of essential oils in citrus hybrid peels
}

\author{
Seon-Dae SHIN ${ }^{1}$, Cheong-Song KIM ${ }^{1}$, Je-Hyuk LEE ${ }^{1 *}$ (D)
}

\begin{abstract}
Satsuma mandarin (Citrus unshiu Marc.), Hallabong [(C. unshiu Marc. $\times$ C. sinensis Osb. $) \times($ C. reticulata Blanco)], Cheonhyehyang $[(($ C. unshiu $\times$ C. sinensis $) \times$ C. reticulata $) \times($ C. reticulate $\times$ C. sinensis $)]$, and Redhyang (citrus hybrid 'Kanpei), which are citrus hybrids, are mostly consumed in Korea. The flavor of citrus peel depends on the composition and content of volatile essential oils. Limonene, $\gamma$-terpinene, $\beta$-myrcene, linalool, ocimene, octanal, and sabinene were found to be the main components in Satsuma mandarin, Hallabong, Cheonhyehyang, Redhyang, and orange (C. sinensis Osb.) peel essential oils. Limonene was the main component (82.05-91.84\%) of all citrus peel essential oils. $\gamma$-Terpinene was present in a particularly high content $(8.09 \%)$ in the essential oil of Satsuma mandarin peel. Linalool was found in the highest proportion (4.39\%) in the essential oil of Cheonhyehyang peels. $\beta$-Ocymene had the highest concentration (6.50\%) in Redhyang peel essential oil. Citrus peel essential oils showed slight antibacterial activity against Salmonella choleraesuis (S. choleraesuis), Bacillus cereus (B. cereus), Listeria monocytogenes (L. monocytogenes), Staphylococcus aureus (S. aureus), and Pseudomonas aeruginosa (P. aeruginosa). Cheonhyehyang peel essential oil showed the highest antibacterial activity against all foodborne pathogens. Additionally, B. cereus was the most sensitive, and S. aureus was the most resistant to the Cheonhyehyang peel essential oil.
\end{abstract}

Keywords: essential oils; citrus hybrids peels; Satsuma mandarin; hallabong; cheonhyehyang; redhyang; orange.

Practical Application: A natural antibacterial material from citrus hybrid peels.

\section{Introduction}

Global citrus production was reported to be 56 million tons in 2018; citrus consumption per capita has increased significantly (United States Department of Agriculture, 2019). Increased production and processing of citrus is accompanied by the formation of a peel by-product. The treatment of large amounts of citrus peel has become an important international environmental and economic issue. In Korea, the production of processed citrus products, such as juice and jam, was approximately 54,997 tons, so it is estimated that a large amount of peel is produced as waste (Korea, 2019). One of the most common ways to use citrus peels is to extract volatile substances from the peel. It is important to obtain accurate information on the chemical composition of the volatile essential oils in citrus peel to promote the use of volatile flavors found in citrus essential oils.

Citrus fruits, including hybrids of Satsuma mandarin, are consumed the most among all fruits in Korea (National Institute of Horticultural and Herbal Science, 2020). Satsuma mandarin (Citrus unshiu Marc.) has a round, flat-shaped, easily removable peel; it is orange-red in color and is sweet and sour. Hallabong $[($ C. unshiu Marc. $\times$ C. sinensis Osb. $) \times($ C. reticulata Blanco)] is a cultivar made by crossing mandarin oranges and oranges, and has peels similar to that of an orange, which is easy to peel. It tastes less sour and is sweeter than oranges.
Cheonhyehyang $[((C$. unshiu $\times$ C. sinensis $) \times C$. reticulata $) \times$ (C. reticulate $\times$ C. sinensis)], a hybrid of tangerines and oranges, is juicy and has a delicate flavor, a strong sweet taste, and a thin peel. Redhyang (citrus hybrid 'Kan Pei') is a citrus breed produced by crossing citrus and Hallabong. Redhyang has redcolored juicy pulp and a strong sweet taste.

Citrus fruits have a unique, refreshing aroma and taste, which affects people's preferences. Satsuma mandarin, Hallabong, Cheonhyehyang, and Redhyang have a unique flavor that is stronger on the peels than on the pulp. The flavor of citrus peel depends on the composition and content of volatile essential oils. The characteristic flavor of mandarin citrus peels-essential oil is due to the combination of numerous compounds such as limonene $+(Z)-\beta$-ocimene, $\gamma$-terpinene, $\alpha$-pinene, $\beta$-pinene, and myrcene (Bonaccorsi et al., 2009). Sabinene, linalool, 4 -terpineol, $\alpha$-pinene, $\beta$-myrcene, $\alpha$-terpinene, $p$-cymene, limonene, $\beta$-ocimene, and $\gamma$-terpinene were identified as the main components of Hallabong peel essential oil (Kim et al., 2013). However, the composition of essential oils varies slightly depending on the method of extraction or analysis, even if the same citrus peels are used. Citrus fruits grown in Korea, such as Satsuma mandarin, Hallabong, and Redhyang, are varieties that have been improved by crossing related varieties. Therefore, there was no significant difference in the composition of the 
essential oil in the skin, and only the content was estimated to be different. In addition, the antimicrobial activity of Korean citrus peel essential oils has not yet been compared and reported.

The purpose of this study was to provide fundamental data on the characteristics of each of the chosen citrus peel essential oils, by comparing the chemical composition and antibacterial activity of Satsuma mandarin, Hallabong, Cheonhyehyang, and Redhyang, and orange peels, which are representative citrus fruits produced or consumed in Korea.

\section{Materials and methods}

\subsection{Citrus hybrid fruits}

Satsuma mandarin (Citrus unshiu Marc.), Hallabong [(C. unshiu Marc. $\times$ C. sinensis Osb. $) \times($ C. reticulata Blanco $)]$, Cheonhyehyang $[(($ C. unshiu $\times C$. sinensis $) \times C$. reticulata $) \times$ (C. reticulate $\times$ C. sinensis)], Redhyang (Citrus hybrid 'Kanpei), and the navel orange (C. sinensis Osb. The Forma Navel) were investigated in this study. Citrus fruits were purchased from a mart in Chungnam, Korea, in March 2018. Peels were separated after washing the fruits and stored at $-80^{\circ} \mathrm{C}$ until the extraction of essential oils.

\subsection{Extraction of essential oils}

The essential oils from citrus peels were extracted using the hydrodistillation method in Clevenger apparatus (Choi, 2012; Osorio et al., 2021). Briefly, the essential oils were separated from citrus peels with $70 \%$ water vapor for $8 \mathrm{~h}$ using an essential oil extractor (EssenLab-Plus, Hanil Labtech, Yangju, Korea). The essential oils were distilled with water vapor and condensed as a supernatant in an essential oil-collecting tube. The essential oils were carefully separated, dehydrated with anhydrous sodium sulfate for $24 \mathrm{~h}$, and then placed in a dark glass bottle and stored at $-20{ }^{\circ} \mathrm{C}$ until analysis.

\subsection{Compositional analysis of essential oils by GC-MS}

The composition of the essential oils was analyzed using an Agilent 7890A GC-5975C MSD system (Agilent Technologies Inc., Santa Ro-sa, CA, USA) at the Center for Research Facilities of Kyungpook National University (http://kpcl.knu.ac.kr/). The components in the essential oil were separated through a $\mathrm{J} \& \mathrm{~W} 122-5532 \mathrm{DB}-5 \mathrm{~ms}(30 \mathrm{~m} \times 0.25 \mathrm{~mm} \times 0.25 \mu \mathrm{m})$ column with helium gas, at a flow rate of $1 \mathrm{~mL} / \mathrm{min}$. The temperature of the injector was $250{ }^{\circ} \mathrm{C}$, and $1 \mu \mathrm{L}$ of the sample was injected through a split injection (split ratio, 100:1). The pressure in the injector was $11.11 \mathrm{psi}$, and the septum purge flow, split flow, and total flow were 3,100 , and $104 \mathrm{~mL} / \mathrm{min}$, respectively. The initial temperature of the column was $50{ }^{\circ} \mathrm{C}$, and the pressure and the average velocity were $11.11 \mathrm{psi}$ and $31.564 \mathrm{~cm} / \mathrm{s}$, respectively. The analysis time per sample was $67.5 \mathrm{~min}$. The column oven was maintained at $50{ }^{\circ} \mathrm{C}$ for $1 \mathrm{~min}$, heated to $180{ }^{\circ} \mathrm{C}$ at a rate of $4{ }^{\circ} \mathrm{C} / \mathrm{min}$, and then heated to $300{ }^{\circ} \mathrm{C}$ at $5{ }^{\circ} \mathrm{C} / \mathrm{min}$, and the highest temperature was $325 \mathrm{C}$. The temperature of the multidimensional scaling plot (MDS) transfer line was $280^{\circ} \mathrm{C}$, and the separated components were analyzed in the range of 30-600 amu at $280{ }^{\circ} \mathrm{C}$, and $70 \mathrm{eV}$ at an interface temperature of $230{ }^{\circ} \mathrm{C}$, using a non-coated EI ion source. Additionally, the electron multiplier voltage (EMV) was 1624 in relative mode, and the MS source and MS Quad were $230{ }^{\circ} \mathrm{C}$ (maximum $250{ }^{\circ} \mathrm{C}$ ) and $150^{\circ} \mathrm{C}$ (maximum $200^{\circ} \mathrm{C}$ ), respectively. Separated peaks of each sample were collected in full scan mode and were identified by comparison with the mass spectral database of the MS library search (NIST, Wiley / NIST).

\subsection{Microorganisms and the anti-bacterial activity}

For the antibacterial assay, Salmonella choleraesuis (S. choleraesuis, KCCM 11806), Bacillus cereus (B. cereus, KCCM 11204), Staphylococcus aureus (S. aureus, KCCM 12214), Pseudomonas aeruginosa (P. aeruginosa, KCCM 11266), and Listeria monocytogenes (L. monocytogenes, KCCM 40307) were obtained from the Korean Culture Center of Microorganisms (KCCM, Seoul, Korea). These foodborne pathogens were cultured in nutrient broth $(\mathrm{NB})$ or brain heart infusion (BHI, $0.5 \% \mathrm{NaCl}$ ) medium for $48 \mathrm{~h}$ at $37^{\circ} \mathrm{C}$ in an incubator.

The antibacterial activity of the essential oils was evaluated using the disc diffusion method (Khan et al., 2017; Al-Nabulsi et al., 2020). Microorganisms were cultured in $100 \mathrm{~mL}$ media for $24 \mathrm{~h}$ at $37^{\circ} \mathrm{C}$ and were diluted to $1 \times 10^{7} \mathrm{cfu} / \mathrm{mL}$ using sterile medium. First, the diluted bacterial suspension $(100 \mu \mathrm{L})$ was spread on an agar plate (NB medium or BHI medium), and a sterile paper disc (diameter $5 \mathrm{~mm}$ ) was placed on the bacteria-spread agar plate. After the essential oil and antibiotics $(10 \mu \mathrm{g})$ were added to the paper disc carefully, the agar plate was incubated for $24 \mathrm{~h}$ at $37^{\circ} \mathrm{C}$. The antibacterial activity of the essential oil was evaluated based on the size of the clear zone around the disc, measured by calipers. Ampicillin and streptomycin were used as positive controls.

\subsection{Statistical analysis}

All data were analyzed statistically using SPSS 24.0 (IBM SPSS Inc., Chicago, IL, USA). Antibacterial data were repeated three times, expressed as mean and standard deviation, and analyzed using one-way analysis of variance (ANOVA) and Duncan's multiple comparison test. Differences were considered significant at $p<0.05$.

\section{Results and discussion}

\subsection{Extraction yield of essential oils from peels of citrus hybrids}

Essential oils were extracted from the peel of five citrus fruits using the steam distillation method, as shown in Table 1. The extraction yields $(\%, \mathrm{v} / \mathrm{w})$ of the essential oils in different

Table 1. Production yield of essential oils from Citrus peels using steam distillation method.

\begin{tabular}{lccc}
\hline \multicolumn{1}{c}{ Citrus } & Peels $(\mathrm{kg})$ & $\begin{array}{c}\text { Essential oils } \\
(\mathrm{ml})\end{array}$ & Yield (\%, v/w) \\
\hline Satsuma mandarin & 6.8 & 5 & 0.073 \\
Hallabong & 6.4 & 7 & 0.109 \\
Cheonhyehyang & 3.9 & 9 & 0.231 \\
Redhyang & 4.4 & 13 & 0.295 \\
Orange & 6.6 & 16 & 0.242 \\
\hline
\end{tabular}


citrus hybrids, were in the order of Redhyang (0.295\%), orange (0.242\%), Chunhyehyang (0.231\%), Hallabong (0.109\%), and Satsuma mandarin (0.073\%). Hallabong, Redhyang, and Cheonhyehyang peels had significantly higher extraction yields than those of Satsuma mandarin peels. Additionally, the flavor of essential oil from the peels of Hallabong, Redhyang, and Cheonhyehyang was stronger than that of Satsuma mandarin (data not shown). Extraction yield of essential oil from Satsuma mandarin peels and orange peels was reported to be approximately 0.24-1.14 and $0.18-0.24 \%$, respectively (Kim et al., 1999), which was similar to this result. Therefore, it was concluded that the extraction of essential oil from citrus peels proceeded correctly. For the extraction of essential oils, the hydro-distillation method is much easier than the low-temperature compression method, or the extraction method using an organic solvent; the extraction yield for the active ingredients, such as limonene, is great (Kim et al., 1999).

\subsection{Composition of essential oils by GC-MS}

The overlap chromatogram of GC-MS analysis of the essential oils of Satsuma mandarin, Hallabong, Cheonhyehyang, Redhyang, and orange peel is shown in Figure 1A. The 11 major constituents among the citrus peel essential oil components were identified in the range of approximately 8 to $15 \mathrm{~min}$ at retention time (RT) at 67.5 min retention time (Figure $1 \mathrm{~B}, \mathrm{C}$ ). The main components identified in the chromatogram were 3 -thujene $(8.207 \mathrm{~min})$, 2-pinene (8.466 $\mathrm{min})$, sabinene (9.729 $\mathrm{min}), 2$ (10) -pinene (9.92 $\mathrm{min}), \beta$-myrcene (10.321 $\mathrm{min})$, octanal (10.737 $\mathrm{min})$, limonene (12.060 $\mathrm{min}), \beta$-ocimene (12.376 $\mathrm{min}), \gamma$-terpinene (12.779 $\mathrm{min}$ ), terpinolene (13.7 $\mathrm{min})$, and linalool (14.190 $\mathrm{min}$ ). The content of components in essential oils differed according to the citrus fruits.

The composition of essential oils in Satsuma mandarin, Hallabong, Cheonhyehyang, Redhyang, and orange peels is shown in Table 2. Limonene was the main component of all citrus peel essential oils, and it was the highest (91.84\%) in orange and the lowest (82.05\%) in Cheonhyehyang (Figure 2). The major compounds with a content ratio of $1 \%$ or more were limonene, $\gamma$-terpinene, linalool, $\beta$-myrcene, $\beta$-ocimene, octanal, and sabinene. In addition, decanal, 11-diene, 2-pinene, a-farnesene, citronellal, citronellol, 2(10)-pinene, (-)-4-terpineol, terpinolene, $\boldsymbol{\alpha}$-terpinene, and 3-thujene were detected in citrus peel essential oils.

Additionally, $\gamma$-terpinene was found in particularly high concentration (8.09\%) in the essential oil of Satsuma mandarin peel (Figure 2). Trace amounts of $\gamma$-terpinene were analyzed in Hallabong, Cheonhyehyang, and orange, but not in Redhyang (Figure 2). Linalool was found in the essential oils of all five citrus peels, and the highest proportion of linalool (4.39\%) was found in the essential oil of Cheonhyehyang peels (Figure 2). The essential oils of Satsuma mandarin, Hallabong, Redhyang, and orange peel had approximately $1-1.73 \%$ linalool. In addition, $\beta$-myrcene was present $(1.50-2.05 \%)$ in the five citrus peel essential oils. $\beta$-ocymene was found to have the highest content $(6.50 \%)$ in Redhyang peel essential oil and was contained in trace amounts of 0.53-1.29\% in Satsuma mandarin and Hallabong peel essential oil. However, $\beta$-ocymene was not detected in the essential oils of Cheonhyehyang and orange peels. Octanal was in the range of $0.30-1.27 \%$ in four citrus peel essential oils, except for Satsuma mandarin (Figure 2). Hallabong peel essential oil contained approximately $3.12 \%$ sabinene, while other citrus essential oils contained approximately $0.13-0.93 \%$ (Figure 2).

\subsection{Composition of essential oil in Satsuma mandarin (Citrus unshiu Marc.) peels}

Seventy-four compounds ( $100 \%$ of total) were separated in the essential oil of Satsuma mandarin peels by GC-MS, and 22 major compounds (99.71\%) were identified (Table 2). Limonene was the most abundant compound (84.59\%) in the essential oil of the peels of Satsuma mandarin (Figure 2). Additionally, $\gamma$-terpinene $(8.09 \%), \beta$-myrcene $(1.68 \%)$, and linalool $(1.00 \%)$ were present in more than $1 \%$ of the essential oil of the peels of Satsuma mandarin. These four compounds accounted for $95.36 \%$ of the total. $\beta$-elemene was detected only in Satsuma mandarin peel essential oils and was not detected in Hallabong, Cheonhyehyang, Redhyang, or orange peel essential oils. However, octanal, citronellal, carvone, and (E)-p-2-menthen1-ol were not found in Satsuma mandarin peel essential oil. The main components of Satsuma mandarin peel-essential oil were known to be limonene, $\gamma$-terpinene, cyclohexane, diethyl phthalate, $\beta$-linalool, $\beta$-myrcene, $\alpha$-farnesene, o-cymene, $\alpha$-pinene, $\alpha$-copaene, $\beta$-elemene, farnesene, and hexadecenoic acid (Kim et al., 1999). Limonene (67.44\%), $\beta$-myrcene (7.15\%), 3 -carene (4.4\%), $\alpha$-pinene (2.52\%), p-cymene (2.43\%), $\beta$-pinene $(1.46 \%)$, sabinene $(0.77 \%)$, terpinolene $(0.47 \%)$, and $\alpha$-thujene $(0.45 \%)$ were the main components of Satsuma mandarin peel essential oil (Tao et al., 2008).

Limonene is composed of two isoprene units with monoterpene hydrocarbons and has a refreshing aroma; it is a major component of essential oils in citrus, such as orange, lemon, tangerine, and lime (Sun, 2007). Limonene is not toxic enough to be classified as generally recognized as safe (GRAS), and is widely used as a flavoring agent in foods such as soup, chewing gum, beverages, fruit juice, soft drinks, confectionery, ice cream, and pudding (Hong \& Kim, 2016b). The daily U.S per capita consumption of limonene is estimated to be approximately $16.2 \mathrm{mg} /$ person/day for adults weighing $60 \mathrm{~kg}$ (Sun, 2007). In addition, limonene has been reported to protect from and improve lung cancer and stomach cancer in the human body and to calm the excitement of the central nervous system (Sun, 2007).

$\gamma$-Terpinene was found to be $8.09 \%$ in Satsuma tangerine peel. According to previous studies (Kim et al., 1999), the content of $\gamma$-terpinene in the essential oil of Satsuma mandarin peels was reported to be $4.66-13.85 \%$, which is similar to the content reported in this study. $\gamma$-Terpinene has been reported to have antioxidant activity against DPPH radicals and an inhibitory effect on the oxidation of LDL cholesterol (Takahashi et al., 2003).

2 -Pinene, which is present in a concentration of $0.82 \%$ in the essential oil of Satsuma mandarin peels, is a major monoterpene compound in plant-derived essential oils (Groot et al., 2002). 2-Pinene has been approved as a safe food additive by the US Food and Drug Administration (FDA) and as a food flavoring ingredient (Food and Drug Administration, 2015). 

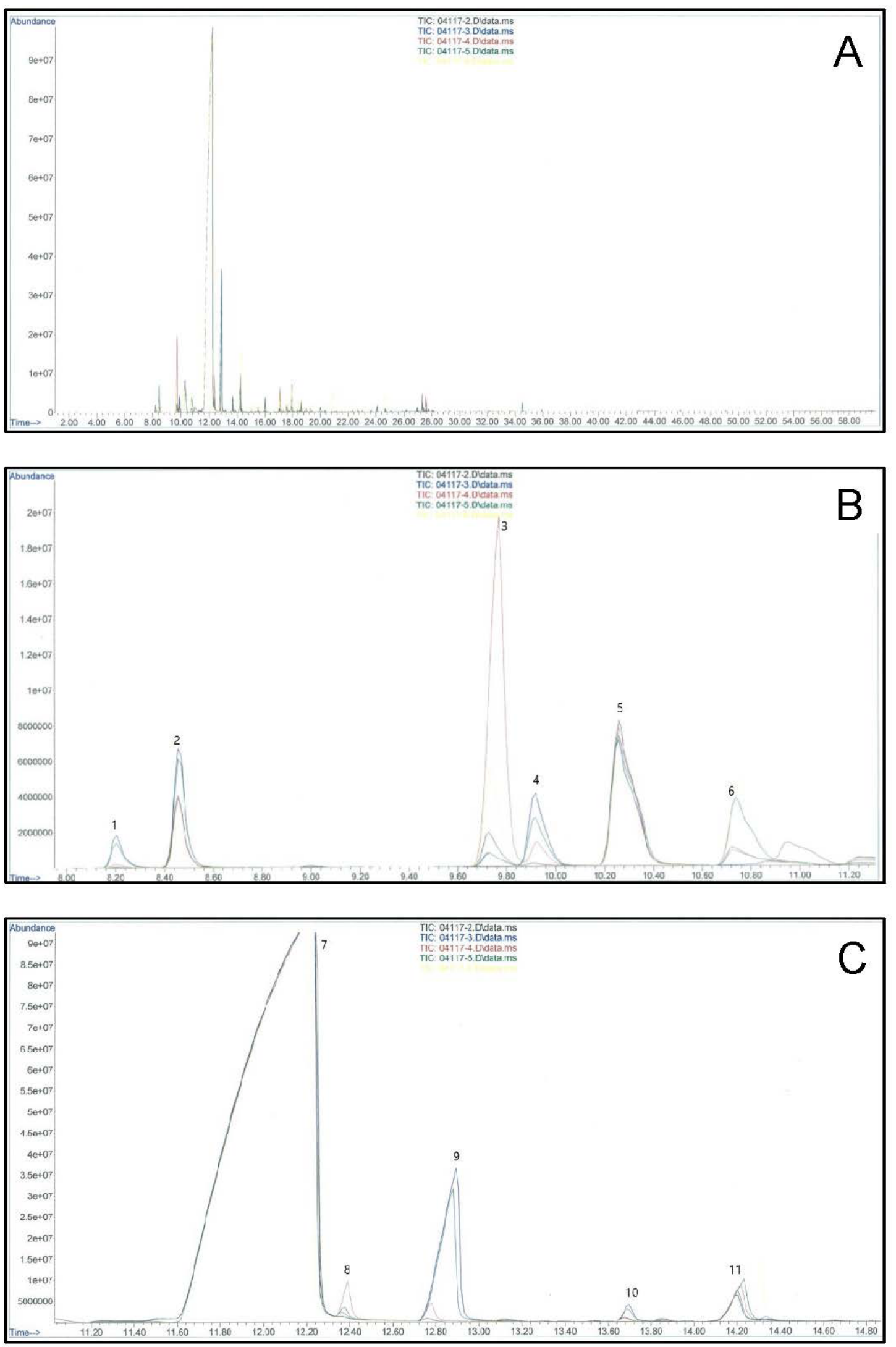

Figure 1. Gas chromatography-mass spectrometry (GC-MS) of citrus peel essential oils. A: Whole scale of gas chromatography for five Citrus peel essential oils (0-67.5 min); B, C: Major peaks of gas chromatography for five Citrus peel essential oils. 1, 3-thujene (8.207); 2, 2-pinene (8.466); 3, sabinene (9.729); 4, 2(10)-pinene (9.92); 5, $\beta$-myrcene (10.321); 6, octanal (10.737); 7, limonene (12.060); 8, $\beta$-ocimene (12.376); 9 , $\gamma$-terpinene (12.779); 10, terpinolene (13.7); 11, linalool (14.190). 
Original Article

Shin; Kim; Lee

Table 2. Essential oil composition of Citrus peel essential oils using GC-MS.

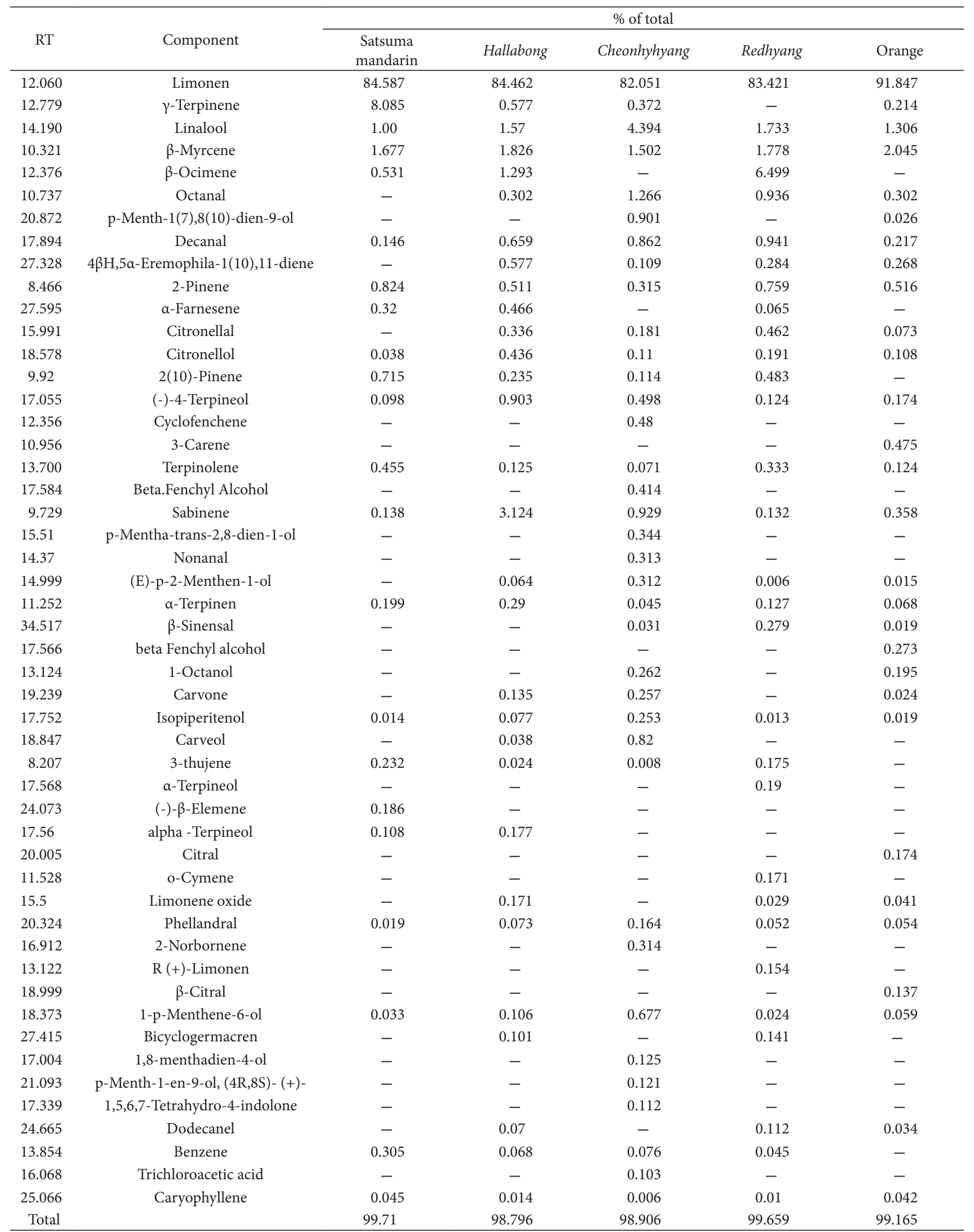



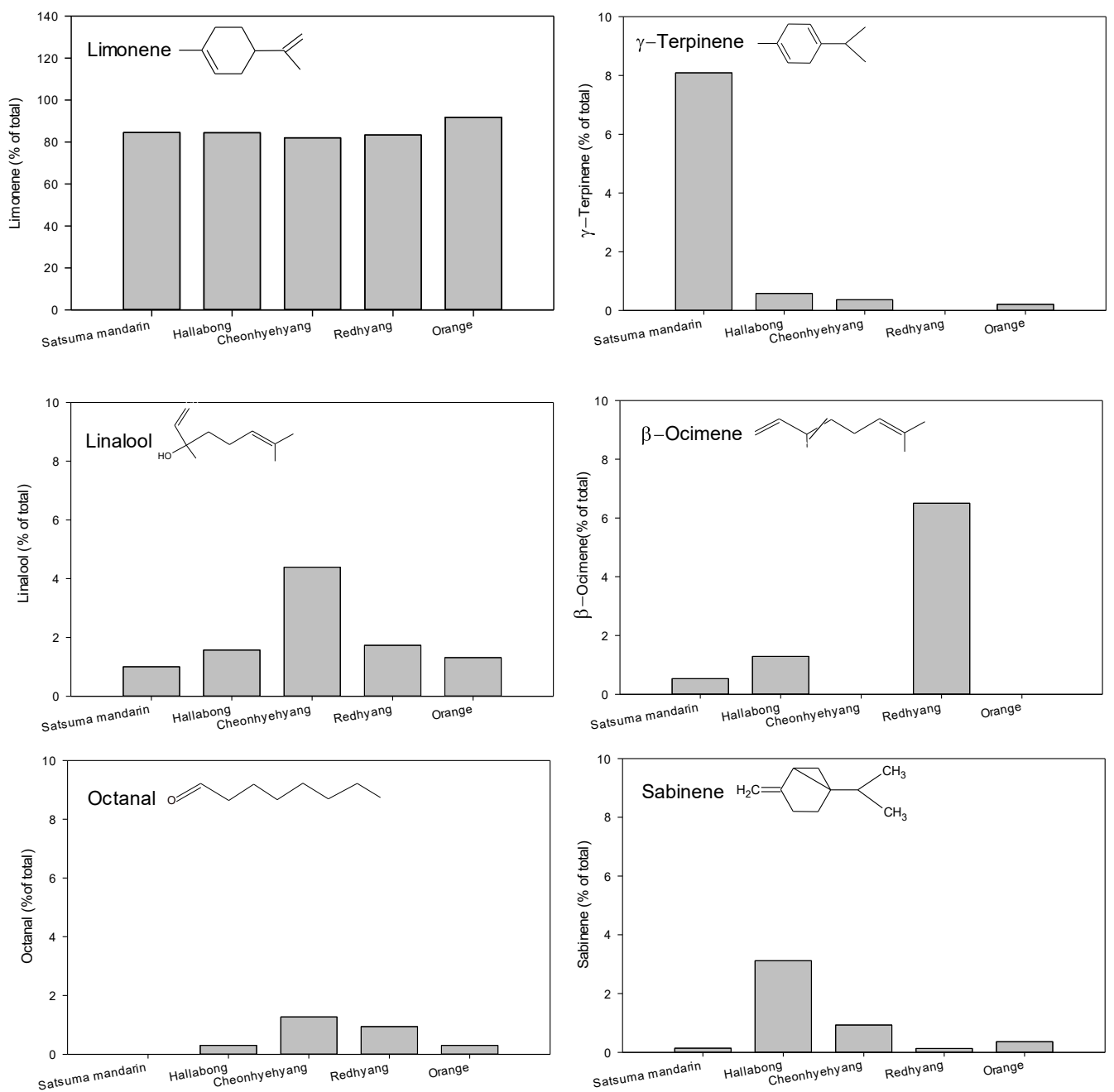

Figure 2. Major components of Citrus peel essential oils.

\subsection{Composition of essential oil in Hallabong [(C . unshiu Marc. $\times$ C. sinensis Osb. $) \times($ C. reticulata Blanco $)]$ peels}

Hallabong peel essential oil was composed of 79 compounds ( $100 \%$ of total) analyzed by GC-MS. Among them, 30 compounds $(98.80 \%)$, identified as the main components, are listed in Table 2. Limonene (84.46\%), sabinene (3.12\%), $\beta$-myrcene (1.83\%), linalool (1.57\%), and $\beta$-ocimene (1.29\%) were the major components of the essential oil of Hallabong peel. Hong and Kim (Hong \& Kim, 2016a) reported 96 compounds, including limonene (62.18\%), $\beta$-myrcene (5.65\%), $\alpha$-pinene (2.49\%), ethyl acetate $(1.26 \%)$, and $\beta$-pinene (1.92\%), from Hallabong peel essential oil. The essential oil composition of Hallabong peel in the previous study was similar to that in this study. Hallabong peel essential oil has been reported to have antioxidant activity against DPPH radicals and anti-inflammatory activity against splenocytes and edema in rats and macrophages (Herath et al., 2016). The activity of Hallabong peel essential oil is thought to be due to several active components constituting the essential oil.

Sabinene is a monoterpenoid called 4(10)-thujene, sabinene, and thuj-4(10)-ene; it has a strong sweet flavor. Sabinene was one of the main ingredients in the essential oils of Satsuma mandarin, Hallabong, Cheonhyehyang, Redhyang, and orange peels (Table 2). In particular, sabinene (3.124\%) was the most abundant in the essential oil of Hallabong peels. Hong and Kim (Hong \& Kim, 2016a) reported that the sabinene contents of Cheonhyehyang and Hallabong essential oils were $6.61 \%$ and $4.06 \%$, respectively. On the other hand, the Jinjihyang, Goldenhyang, and Redhyang essential oils contained a small amount of sabinene in the range of 0.44-1.44\% (Hong \& Kim, 2016a). Hallabong peels essential oil has significantly higher sabinene content than lemon, orange, and grape peel essential oils (Yoo et al., 2004).

\subsection{Composition of essential oil in Cheonhyehyang $[((($ Unshiu $\times$ C. sinensis $)) \times$ C. reticulata $) \times($ C. reticulata $\times$ C. sinensis)] peels}

Seventy-six compounds ( $100 \%$ of total) were detected in the essential oil of Chunhyehyang peels, of which 36 compounds (98.91\%) were identified as major components, as shown in Table 2. Limonene was the most abundant compound (82.05\%), followed by linalool (4.39\%), $\beta$-mycrene (1.50\%), and octanal 
(1.27\%). These four compounds accounted for approximately $89.21 \%$ of the Chunhyehyang peel essential oil. In addition, cyclofenchene, nonanal, p-mentha-trans-2,8-dien-1-ol, 2-norbornene, 1,8-menthadien-4-ol, p-menth-1-en-9-ol, (4R,8S)(+)-,1,5,6,7-tetrahydro-4-indolone, and trichloroacetic acid were detected only in the essential oil of Chunhyehyang peels.

Hong \& Kim (2016a) reported that limonene (42.57\%), sabinene (6.61\%), linalool (5.17\%), decanal (3.73\%), limonene-10-ol (3.01\%), 4-terpineol (2.65\%), $\beta$-myrcene $(2.58 \%)$, and $\beta$-pinene $(2.32 \%)$ were detected in the essential oil of Cheonhyehyang peels. Although, ethyl benzene, nonanol, 1-p-menthen-9-al, (E) isocarveol, methyl salicylate, and $\alpha$-terpinen-7-al were unique volatile fragrance components found only in Cheonhyehyang (Hong \& Kim, 2016a), these were not detected in this study. Chunhyehyang peel essential oil contains 2.54 to 4.39 times more linalool than the other four citrus fruits (Table 2). Linalool inhibits glutamatergic transmission in the central nervous system (CNS), as well as antibacterial and antifungal activities (Buchbauer et al., 1991).

\subsection{Composition of essential oil in Redhyang (citrus hybrid 'Kanpei) peels}

Redhyang peel essential oil contained 57 compounds (100\% of total), of which 30 compounds (99.66\%) are listed in Table 2. Limonene had the highest content $(83.42 \%)$, followed by $\beta$-ocimene (6.50\%), $\beta$-mycrene (1.78\%), and linalool (1.73\%). In the essential oil of Redhyang peel, $\beta$-ocimene (6.50\%) showed approximately 12.26 and 5.04 times higher concentration than Satsuma mandarin (0.53\%) and Hallabong (1.29\%), respectively (Figure 2). Additionally, $\beta$-ocimene was not found in Chunhyehyang and orange peel essential oils. On the other hand, $\gamma$-terpinene was relatively high in Satsuma mandarin, Hallabong, Cheonhyehyang, and orange peel essential oils, but was not detected in Redhyang.

Redhyang peel essential oil contained limonene (51.38\%), $\beta$-myrcene (7.23\%), linalool (4.81\%), decanal (4.32\%), $\alpha$-pinene (4.23\%), $\alpha$-sinensal (3.13\%), $\beta$-pinene (2.48\%), citronellal (1.97\%), $\alpha$-phellandrene (1.91\%), octanal (1.45\%), and $\alpha$-thujene $(1.23 \%)$ (Hong \& Kim, 2016a). $\rho$-Cymen-8-ol, bornyl acetate, carvacrol, and bicycloelemene were found in trace quantities in Redhyang peel essential oil. In addition, $\gamma$-terpinene $(0.68 \%)$ was present in Redhyang peel essential oil (Hong \& Kim, 2016a), but was not detected in this study.

$\beta$-Ocimene is present in Redhyang peel essential oil in a larger amount than in other Citrus fruits, and exhibits floral sweetness (Shimoda et al., 2012). $\beta$-Ocimene is a component of essential oils in Bidens pilosa (Linn. Var. Radita), used for food storage purposes (Goudoum et al., 2016), in Ocimum gratissimum, which inhibits pests that cause damage to stored foods, and in Phlomis sp., which has antibacterial activity against food-poisoning bacteria (Ogendo et al., 2008).

\subsection{Composition of essential oil in Navel orange peels}

Orange peel essential oil was composed of 77 compounds ( $100 \%$ of the total, data not shown). Among them, 29 compounds (99.17\%) identified as the main components are listed in Table 2.
Limonene (91.85\%) was the most abundant component, followed by $\beta$-mycrene $(2.05 \%)$ and linalool $(1.31 \%)$ in orange peel essential oil. These three compounds accounted for $95.21 \%$ of the compounds in orange peel essential oil. In particular, among the five citrus fruits used in this study, limonene had the highest content $(91.85 \%)$ in orange peel essential oil. The other four citrus peel essential oils contained approximately $82.05-84.59 \%$ limonene. $\beta$-Mycrene had a higher content $(2.05 \%)$ in orange peel essential oil than in the essential oils of Satsuma mandarin, Hallabong, Cheonhyehyang, and Redhyang. Cyclofenchene, $\beta$-fenchyl alcohol, citral, and $\beta$-citral were analyzed only in orange peel essential oil, but 2 (10)-pinene, 3-thujene, and benzene were not detected.

Hong \& Kim (2016a) reported that limonene (66.70\%), $\beta$-mycrene (10.89\%), $\delta$-3-carene (3.88\%), $\alpha$-pinene $(3.16 \%)$, sabinene (1.84\%), and linalool (1.80\%) were detected in orange peel essential oil. Limonene, $\gamma$-terpinene, $\beta$-mycrene, and $\alpha$-pinene were also analyzed as major components of orange peel essential oil (Liu et al., 2019), similar to the contents in this study.

$\beta$-Myrcene, an acyclic monoterpene, is a compound that is present in higher concentration in orange peel essential oil than in essential oils of other citrus fruits, and is contained in essential oils of lemon glass and hops. $\beta$-Myrcene has long been used as a fragrance for food additives, soaps, and cosmetics (Ciftci et al., 2014). $\beta$-Myrcene provides analgesic, anti-inflammatory, anti-ulcer, and antioxidant activity, and improves stroke symptoms by preventing tissue oxidation and histological damage (Ciftci et al., 2014).

\subsection{Antibacterial activity of essential oils in peels of citrus hybrids against foodborne pathogens}

The antimicrobial activity of citrus peel essential oils against foodborne pathogens is shown in Table 3. Citrus peel essential oils showed slight antibacterial activity against $S$. choleraesuis, $B$. cereus, L. monocytogenes, $S$. aureus, and $P$. aeruginosa, with some differences in strength and weakness. Citrus peel essential oils showed antibacterial activity regardless of the gram-negative and gram-positive bacteria used in the experiment. Among the five essential oils, Chunhyehyang peel essential oil showed the highest antibacterial activity against all foodborne pathogens. Additionally, B. cereus was the most sensitive, and $S$. aureus was the most resistant to the Chunhyehyang peel essential oil. The control antibiotic, streptomycin, showed antimicrobial activity against all food-poisoning bacteria.

Citrus unshju peel essential oil has been reported to have antibacterial activity against Salmonella typhimurium, Escherichia coli (E. coli), S. aureus, and B. cereus (Ahn et al., 2007). Orange (Citrus sinensis) peel essential oil, which contains limonene and $\beta$-myrcene as the main components, showed antibacterial activity against Saccharomyces cerevisiae, E. coli, Bacillus subtilis, and $S$. aureus (Guo et al., 2018). In addition, $\alpha$-pinene, $\beta$-pinene, and limonene, which are the main components of citrus peel essential oils, showed antimicrobial activity against $S$. aureus (Pulaj et al., 2016), and linalool and $\alpha$-terpineol suppressed the growth of periodontopathic and cariogenic bacteria (Park et al., 2012). There are few reports on the antimicrobial 
Table 3. Anti-bacterial activity of citrus peel essential oils.

\begin{tabular}{lccccc}
\hline & $\begin{array}{c}\text { Salmonella } \\
\text { choleraesuis }(-)^{*}\end{array}$ & $\begin{array}{c}\text { Bacillus } \\
\text { cereus }(+)^{*}\end{array}$ & $\begin{array}{c}\text { Listeria } \\
\text { monocytogenes }(+)\end{array}$ & $\begin{array}{c}\text { Staphylococcus } \\
\text { aureus }(+)\end{array}$ & $\begin{array}{c}\text { Pseudomonas } \\
\text { aeruginosa }(+)\end{array}$ \\
\hline Satsuma mandarin & $0.50 \pm 0.50^{1)}$ & $0.92 \pm 1.18$ & $0.08 \pm 0.14$ & $\mathrm{ND}^{2)}$ & $0.17 \pm 0.29$ \\
Cheonhyhyang & $0.83 \pm 0.29$ & $1.17 \pm 0.29$ & $0.67 \pm 0.52$ & $0.17 \pm 0.29$ & $0.83 \pm 0.29$ \\
Hallabong & $\mathrm{ND}$ & $\mathrm{ND}$ & $\mathrm{ND}$ & $0.10 \pm 0.00$ & $\mathrm{ND}$ \\
Redhyang & $0.50 \pm 0.00$ & $0.75 \pm 0.25$ & $0.33 \pm 0.29$ & $0.17 \pm 0.29$ & $0.67 \pm 0.29$ \\
Orange & $0.58 \pm 0.14$ & $1.00 \pm 0.00$ & $0.33 \pm 0.29$ & $0.00 \pm 0.00$ & $0.67 \pm 0.58$ \\
Streptomycin & $3.08 \pm 0.14$ & $6.33 \pm 0.58$ & $1.17 \pm 0.72$ & $3.50 \pm 0.00$ & $2.67 \pm 0.58$ \\
\hline
\end{tabular}

"(-): gram negative, (+); gram positive. ${ }^{1)}$ Size of clear zone (mm). ${ }^{2} \mathrm{ND}$ : not detected. All essential oils (10 mg/disc) and streptomycin $(12.5 \mu \mathrm{g} /$ disc) were used for the disc diffusion assay.

activity of Cheonhyehyang, Redhyang, and Hallabong essential oils. Cheonhyehyang, Redhyang, and Hallabong essential oils are considered to exert antibacterial activity because they contain antimicrobial limonene, $\alpha$-pinene, and $\beta$-pinene.

\section{Conclusion}

The essential oil from Satsuma mandarin, Hallabong, Cheonhyehyang, Redhyang, and orange had limonene, $\gamma$-terpinene, linalool, $\beta$-myrcene, $\beta$-ocimene, octanal, and sabinene as the main component. Cheonhyehyang, Redhyang, and Hallabong essential oils exerted antibacterial activity against some foodborne pathogens. From these results, it is expected that Citrus peel essential oil can be used as a fragrance with antibacterial activity.

\section{Acknowledgements}

This work was supported by the research grant of the Kongju National University in 2018.

\section{References}

Ahn, M. S., Kim, H. J., \& Seo, M. S. (2007). A study on the antioxidative and antimicrobial activities of the Citrus unshju peel extracts. Korean Journal of Food Culture, 22(4), 454-461. [In Korean].

Al-Nabulsi, A., Osaili, T., Olaimat, A., Almasri, W., Al-Holy, M., Jaradat, Z., Ayyash, M., Awaisheh, S., \& Holley, R. (2020). Inhibitory effect of thyme and cinnamon essential oils against E. coli O157:H7 in Tahini. Food Science and Technology, 40(4), 885-893. http://dx.doi. org/10.1590/fst.21619.

Bonaccorsi, I., Dugo, P., Trozzi, A., Cotroneo, A., \& Dugo, G. (2009). Characterization of mandarin (Citrus deliciosa Ten.) essential oil. Determination of volatiles, non-volatiles, physico-chemical indices and enantiomeric ratios. Natural Product Communications, 4(11), 1595-1600. http://dx.doi.org/10.1177/1934578X0900401128. PMid:19967998.

Buchbauer, G., Jirovetz, L., Jager, W., Dietrich, H., \& Plank, C. (1991). Aromatherapy: evidence for sedative effects of the essential oil of lavender after inhalation. Zeitschrift für Naturforschung, 46(11-12), 1067-1072. http://dx.doi.org/10.1515/znc-1991-11-1223. PMid:1817516.

Choi, H. S. (2012). GC-MS Analyses of the essential oils from Ixeris dentate (Thunb.) Nakai and I. stolonifera A. Gray. Korean Journal of Food and Nutrition, 25(2), 274-283. http://dx.doi.org/10.9799/ ksfan.2012.25.2.274. [In Korean].

Ciftci, O., Oztanir, M. N., \& Cetin, A. (2014). Neuroprotective effects of $\beta$-myrcene following global cerebral ischemia/reperfusion-mediated oxidative and neuronal damage in a C57BL/J6 Mouse. Neurochemical
Research, 39(9), 1717-1723. http://dx.doi.org/10.1007/s11064-0141365-4. PMid:24972849.

Food and Drug Administration - FDA. (2015). Code of Federal Regulations Title 21. Washington, DC: National Archives and Records Administration.

Goudoum, A., Abdou, A. B., Ngamo, L. S. T., Ngassoum, M. B., \& Mbofung, C. M. F. (2016). Antioxidant activities of essential oil of Bidens pilosa (Linn. Var. Radita) used for the preservation of food qualities in North Cameroon. Food Science \& Nutrition, 4(5), 671678. http://dx.doi.org/10.1002/fsn3.330. PMid:27625769.

Groot, P., Nott, R., \& MacDonald, L. (2002). Influence of enantiomers of a-pinene on the response of the red pine cone beetle, Conophthorus resinosae to its pheromone pityol. Entomologia Experimentalis et Applicata, 105(2), 169-174. http://dx.doi.org/10.1046/j.15707458.2002.01045.x.

Guo, Q., Liu, K., Deng, W., Zhong, B., Yang, W., \& Chun, J. (2018). Chemical composition and antimicrobial activity of Gannan naval orange (Citrus sinensis Osbeck cv. Newhall) peel essential oils. Food Science \& Nutrition, 6(6), 1431-1437. http://dx.doi.org/10.1002/ fsn3.688. PMid:30258585.

Herath, K. H., Bing, S. J., Cho, J., Kim, A., Kim, G. O., Lee, J. C., \& Jee, Y. (2016). Citrus Hallabong [(Citrus unshiu $\times$ C. sinensis $) \times$ C. reticulata $)]$ exerts potent anti-inflammatory properties in murine splenocytes and TPA-induced murine ear edema model. Pharmaceutical Biology, 54(12), 2939-2950. http://dx.doi.org/10.1080/13880209.2016.1194 865. PMid:27333995.

Hong, Y. S., \& Kim, K. S. (2016a). Identification of volatile flavor compounds in Jeju citrus fruits. Korean Journal of Food Preservation, 23(7), 977-988. http://dx.doi.org/10.11002/kjfp.2016.23.7.977. [In Korean].

Hong, Y. S., \& Kim, K. S. (2016b). Determination of the volatile flavor components of orange and grapefruit by simultaneous distillationextraction. Korean Journal of Food Preservation, 23(1), 63-73. http:// dx.doi.org/10.11002/kjfp.2016.23.1.63. [In Korean].

Khan, B. M., Bakht, J., \& Shafi, M. (2017). Screening of leaves extracts from Calamus aromaticus for their antimicrobial activity by disc diffusion assay. Pakistan Journal of Pharmaceutical Sciences, 30(3), 793-800. PMid:28653924.

Kim, M. J., Yang, K. W., Kim, S. S., Park, S. M., Park, K. J., Kim, K. S., Choi, Y. H., Cho, K. K., Lee, H., \& Hyun, C. G. (2013). Chemical composition and anti-inflammatory effects of essential oil from Hallabong flower. EXCLI Journal, 12, 933-942. PMid:27366141.

Kim, Y. K., Hyun, S. W., \& Ko, Y. H. (1999). Analysis of essential oils from the peel of mandarine (Citrus unshiu Marc. Var. Okitsu). Korean Journal of Food Science Technology, 31(5), 1178-1183. [In Korean].

National Institute of Horticultural and Herbal Science (2020) Basic statistics of fruits [In Korean]. Retrieved from https://www.nihhs. go.kr/farmer/statistics/statistics.do?t_cd=0203. 
Korea, Ministry of Food Agriculture, Forestry and Fisheries. (2019). 2018 fruit processing status [In Korean]. Retrieved from https://lib. mafra.go.kr/skyblueimage/262.pdf.

Liu, K., Deng, W., Hu, W., Cao, S., Zhong, B., \& Chun, J. (2019). Extraction of 'Gannanzao' orange peel essential oil by response surface methodology and its effect on cancer cell proliferation and migration. Molecules, 24(3), 499-510. http://dx.doi.org/10.3390/ molecules24030499. PMid:30704118.

Ogendo, J. O., Kostyukovsky, M., Ravid, U., Matasyoh, J. C., Deng, A. L., Omolo, E. O., Kariuki, S. T., \& Shaaya, E. (2008). Bioactivity of Ocimum gratissimum L. oil and two of its constituents against five insect pests attacking stored food products. Journal of Stored Products Research, 44(4), 328-334. http://dx.doi.org/10.1016/j.jspr.2008.02.009.

Osorio, P. R. A., Costa, P. F., Dalcin, M. S., Mourão, D. S. C., Aguiar, R. W. S., Oliveira, G. R. A. S., Farias, D. I. O. A., Dias, F. R., \& Santos, G. R. (2021). Medicinal plant essential oils associated with biofilm to protect papaya fruits. Food Science and Technology, 41(Suppl. 1), 386-392. http://dx.doi.org/10.1590/fst.16620.

Park, S. N., Lim, Y. K., Freire, M. O., Cho, E., Jin, D., \& Kook, J. K. (2012). Antimicrobial effect of linalool and a-terpineol against periodontopathic and cariogenic bacteria. Anaerobe, 18(3), 369-372. http://dx.doi.org/10.1016/j.anaerobe.2012.04.001. PMid:22537719.

Pulaj, B., Mustafa, B., Nelson, K., Quave, C. L., \& Hajdari, A. (2016). Chemical composition and in vitro antibacterial activity of Pistacia terebinthus essential oils derived from wild populations in Kosovo.
BMC Complementary and Alternative Medicine, 16(1), 147-155. http://dx.doi.org/10.1186/s12906-016-1135-8. PMid:27229927.

Shimoda, T., Nishihara, M., Ozawa, R., Takabayashi, J., \& Arimura, G. (2012). The effect of genetically enriched (E)- $\beta$-ocimene and the role of floral scent in the attraction of the predatory mite Phytoseiulus persimilis to spider mite-induced volatile blends of torenia. New Phytologist, 193(4), 1009-1021. http://dx.doi.org/10.1111/j.14698137.2011.04018.x. PMid:22243440.

Sun, J. (2007). D-Limonene: safety and clinical applications. Alternative Medicine Review, 12(3), 259-264. PMid:18072821.

Takahashi, Y., Inaba, N., Kuwahara, S., \& Kuki, W. (2003). Effects of $\gamma$-terpinene on lipid concentrations in serum using triton ER1330treated rats. Bioscience, Biotechnology, and Biochemistry, 67(11), 2448-2450. http://dx.doi.org/10.1271/bbb.67.2448. PMid:14646206.

Tao, N. G., Liu, Y. J., Zhang, J. H., Zeng, H. Y., Tang, Y. F., \& Zhang, M. L. (2008). Chemical composition of essential oil from the peel of Satsuma mandarin. African Journal of Biotechnology, 7(9), 1261-1264.

United States Department of Agriculture - USDA. (2019). Citrus: world markets and trade. Retrieved from https://www.fas.usda.gov/data/ citrus-world-markets-and-trade.

Yoo, Z. W., Kim, N. S., \& Lee, D. S. (2004). Comparative analyses of the flavors from Hallabong (Citrus sphaerocarpa) with lemon, orange and grapefruit by SPTE and HS-SPME combined with GC-MS. Bulletin of the Korean Chemical Society, 25(2), 271-279. http://dx.doi. org/10.5012/bkcs.2004.25.2.271. 